\title{
Creativity, perceptual stability, and self-perception
}

\author{
BRUCE O. BERGUM and JUDITH E. BERGUM \\ Texas A\&M University, College Station, Texas 77843
}

\begin{abstract}
The hypothesis that self-perceived creativity is associated with relatively high perceptual instability was tested. Observed reversals of ambiguous two-dimensional figures were compared for 25 architecture and 25 business administration undergraduate majors, as were biographical and adjective checklist measures of self-perception. The results indicated a significant $(p<.01)$ difference in the predicted direction for number of reversals, with the architecture students also perceiving themselves as more creative, original, and visually oriented than the business administration students. An electronic/neurological analogy was suggested in explanation of the results.
\end{abstract}

Professors in different areas differ importantly in their self-perceptions, particularly in regard to the trait of creativity (B. Bergum, 1973, 1974, 1975). Thus, productive academic publishers and industrial and academic inventors see themselves as more creative than their less productive colleagues. This "creative" selfpercept is most notable among those individuals engaged in activities involving a large component of visual imagery, suggesting the obvious fact that to be creative in this kind of activity, one must literally "see" the world differently than others do. A possible mechanism relating to this ability might be the extent to which individuals differ in their visual perceptual stability as measured by their responses to ambiguous stimulus figures. The results of a recent study (B. Bergum \& Flamm, 1975) employing such figures as the Necker cube tended, although not significantly, to support this hypothesis.

To the extent that self-perception can be construed as one aspect of personality, such results would seem to imply a relationship between personality and perceptual stability, as has been noted by several writers (Mason, Kaszor, \& Bourassa, 1973), although neither factor analysis (Thurstone, 1944) nor Rorschach (Smith, Imparto, \& Exner, 1968) techniques have demonstrated this relationship. However, these particular studies did not employ self-perceptual measures of personality, and the question can be approached from another perspective.

Flamm and B. Bergum (1977), noting a difference in the frequency of reversal responses to the Necker cube and the Rubin vase figure, hypothesized that these might result from differences in the perceived tridimensionality of the two figures, and in a subsequent study (Flamm \& B. Bergum, 1978) demonstrated this to be the case. An implication of this finding is that individuals who are more inclined to perceive twodimensional figures as three-dimensional representations are more likely to experience more figure reversals.
Thus, professionals who are more dependent upon such perceptions should also experience more reversals. Our first hypothesis, then, was that architects, who are necessarily very involved in visual images, would observe more reversals than other individuals, such as business people, who are not so involved.

That architects are commonly thought to be more visually creative than business people led to the additional hypothesis that the self-percepts of these groups would tend to conform to this population stereotype, since they are themselves part of this general population.

Finally, it was hypothesized that individuals who display high levels of perceptual instability are rewarded by success in certain kinds of activities that are frequently associated with the concept of creativity, thus giving rise to a strong self-perception of creativity because of the personal characteristics they themselves bring to the situation. Given a strong and frequently rewarded self-concept of creativity, other basic individual differences such as sex should be unrelated to degree of perceptual instability.

\section{METHOD}

\section{Subjects}

Fifty undergraduate students at Texas A\&M University served as the subjects in this experiment. Of these, 25 (19 males, 6 females) were from the School of Architecture, and 25 (20 males, 5 females) were from the School of Business Administration.

\footnotetext{
Apparatus

The apparatus consisted of a Sawyers Model 500 35-mm slide projector and a cassette tape recorder with a prerecorded tape for playback control of the 60 -sec slide-presentation intervals. Materials included six slides depicting six common ambiguous figures, including the Necker cube, the Mach figure, a variation on the Schroeder stair figure, the Rubin vase figure, the truncated pyramid figure, and the Jastrow rabbit-duck figure (Attneave, 1971). In each case, a small red fixation dot was centered in the middle of the slide.
} 
Additional materials included a 20 -item biographical inventory (B. Bergum, 1973) and a 33-item adjective checklist (Gough, 1960) employed in a series of related earlier studies (B. Bergum, 1973, 1974, 1975).

\section{Procedure}

All subjects were first asked to respond to the biographical and checklist forms; upon completion, they were instructed in the procedures for the figure reversal phase of the study, in which they were shown two demonstration slides of reversible figures and were invited to observe the nature of the reversal experience. The subjects were instructed to fixate on the red dot in each figure throughout the testing period and to indicate by a mark in their response booklets each time they experienced a reversal in the figure without looking away from the figure.

The six test figures were then displayed for $60 \mathrm{sec}$ in two random orders. This procedure was employed to control for potential sequential and positional effects of the stimuli, as well as for differences in the basic reversibility of the figures.

\section{RESULTS AND DISCUSSION}

The results were analyzed first in terms of the total number of reversals for all stimulus figures and for each subject, with these data then serving as the basis for comparison between architecture (A) and business administration (B) subjects. As anticipated, Group A showed a greater total number of reversals (797) than did Group B (478). These data were subjected to a Mann-Whitney $U$ test that indicated that the $67 \%$ higher rate of reversals for Group A was highly significant $(\mathrm{z}=3.09, \mathrm{p}<.01)$.

In terms of self-perception, the results for the biographical inventory were subjected to chi-square analyses of the frequencies with which the items were responded to by the groups. Three of the 20 analyses yielded significant differences. Group A subjects saw themselves as more creative $\left(100 \%\right.$ vs. $68 \% ; \chi^{2}=9.52$, $\mathrm{p}<.01)$ and more reliant upon visual images $(96 \%$ vs. $72 \% ; \chi^{2}=5.36, p<.05$ ), while Group B subjects saw themselves as more interested in administrative work $\left(68 \%\right.$ vs. $\left.24 \% ; \chi^{2}=9.74, p<.01\right)$. These results are similar to those found in earlier work with highly creative professionals (B. Bergum, 1973, 1974, 1975; B. Bergum \& Cooper, 1977; Morris \& B. Bergum, 1978), and they provide validating support for the assumption that the selected groups differ basically in their perceptions of themselves.

Analysis of the adjective checklist data provides further support for this conclusion. In this case, 4 of the 33 adjectives yielded chi-square values of significance. Group A subjects saw themselves as more original $\left(88 \%\right.$ vs. $\left.40 \% ; \chi^{2}=12.50, \mathrm{p}<.01\right)$, more moody (60\% vs. $24 \% ; \chi^{2}=6.65, p<.01$ ), and more idealistic $\left(56 \%\right.$ vs. $\left.25 \% ; \chi_{1}^{2}=5.33, p<.05\right)$, while Group B subjects saw themsleves as more mannerly than did the Group A subjects $\left(68 \%\right.$ vs. $\left.40 \% ; \chi_{1}^{2}=3.94, p<.05\right)$.

Finally, analysis of the data for all measures in terms of sex indicated no differences in terms of reversal rates or self-perceived creativity. These results are in line with the implications of an earlier study in which the sexes were found not to differ in terms of this characteristic (B. Bergum \& J. E. Bergum, 1978).

In general, the results support the hypothesis that those individuals associated with activities that rely heavily upon visual manipulation display higher reversal rates than individuals in professional areas in which such characteristics are either irrelevant or unimportant. The hypothesis that these groups differ in terms of their self-perceptions of creativity and originality was also supported.

In terms of the process giving rise to the observed effects, one possibility is that visual creativity may be determined as much by a neurological tendency toward perceptual instability as by the effects of learning. A potential mechanism has been suggested by Attneave (1971), who draws an analogy between perceptual stability and electronic circuits. Following this notion, if electronic flip-flop circuits, involving alternative capacitance loads, can be thought of as varying from individual to individual in terms of specific thresholds for discharge, then architects might be characterized as having lower neurological capacitor values than administrators. Given this basis, the perception of one's own creativity might be a learned discrimination resulting from his experience with the rewarding effects of such perceptual instability.

\section{REFERENCES}

Attneave, F. Multistability in perception. Scientific American, 1971, 225(6), 62-71.

Bergum, B. Selection of specialized creators. Psychological Reports, 1973, 33, 635-639.

BERGUM, B. Self-perceptions of members of a graduate faculty whose publication rates are high or low. Psychological Reports, 1974, 35, 857-858.

BERGUM, B. Self-perceptions of creativity among academic inventors and non-inventors. Perceptual and Motor Skills, 1975, 40, 78.

Bergum, B., \& Bergum, J. E. Sex-role self-perceptions and sex-role stereotypes. Perceptual and Motor Skills, 1977, 44, 1015-1019.

Bergum, B., \& CoOper, T. Undergraduate self-perceptions of creativity and independence. Perceptual and Motor Skills, 1977, 44, 186-190.

Bergum, B., \& Flamm, L. E. Perceptual stability, image size, binocularity and creativity. Perceptual and Motor Skills, 1975 , 41, 667-671.

Flamm, L. E., \& Bergum, B. Reversible perspective figures and eye movements. Perceptual and Motor Skills, 1977, 44, 1015-1019.

Flamm, L. E., \& Bergum, B. Perceived tridimensionality and the reversibility of geometric figures. Whippany, N.J: Bell Laboratories, 1978. (Case 39023-90)

Gough, H. G. Techniques for identifying the creative research scientist. In D. W. MacKinnon (Ed.), The creative person. Berkeley: University of California Extension, 1960.

Mason, J., Kaszor, P., \& Bourassa, C. M. Perceptual structure of the Necker cube. Nature, 1973, 244, 54-56.

Morris, T. L., \& Bergum, B. A note on the relationship 
between field-independence and creativity. Perceptual and Motor Skills, 1978, 46, 1114.

Smith, O. W., Imparto, N., \& Exner, J. C., Jr. Effects of practice on reversals of incomplete Necker cubes. Perceptual and Motor Skills, 1968, 27, 951-954.
Thurstone, E. L. A factorial study of perception. Psychometric Monographs, 1944, No. 4.

(Received for publication April 11, 1979.) 